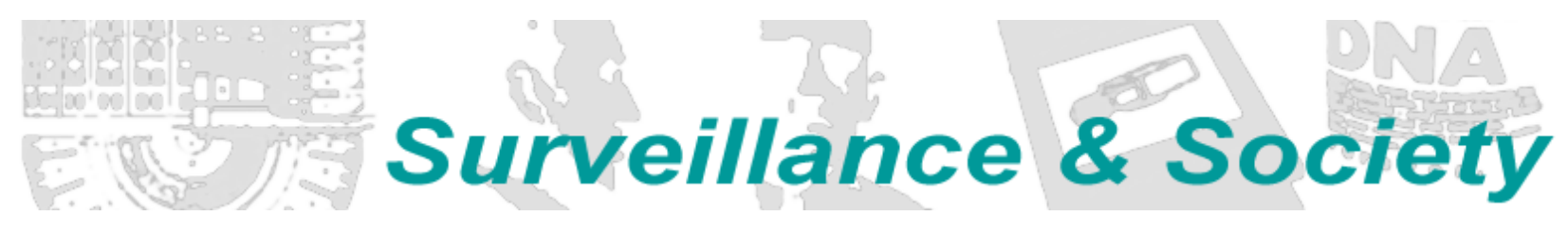

\title{
Article | Amazon: Surveillance as a Service
}

\section{Emily West}

University of Massachusetts, Amherst, USA

ewest@comm.umass.edu

\begin{abstract}
This essay argues that Amazon, the leading e-commerce platform in many parts of the world, uses surveillance not just as a key tool in the platform logic of its growing constellation of businesses but also increasingly as a service to its consumers. In contrast to prevailing assumptions that platforms will obscure the surveillant aspects of their businesses and that users will resist the intrusive nature of corporate surveillance, Amazon's business practices point to the rapid normalization, and even embrace, of surveillant logics by consumers. Given the importance of consumer data to its operations, Amazon increasingly designs services whose purpose is, at least in part, to collect more data about consumers. The zenith of Amazon's surveillance capabilities of its customers is no doubt its family of Echo devices enabled by the artificial intelligence interactive-voice service Alexa, which connects to the cloud run by Amazon, itself, through Amazon Web Services. Alexa is similar to competing digital voice assistants like Apple's Siri and Google's Assistant, but with more cultural visibility, worldwide market penetration, and greater integration with a host of Internetof-Things devices produced by a variety of manufacturers. Amazon seeks to make Alexa an indispensable service to consumers, one that sweetens the granular forms of surveillance in more private spaces and situations that it now has the capability to gather, relative to the company's more established forms of surveillance. While a typical association with surveillance might be the alienation and disempowerment of social control, I suggest that Amazon's practices of consumer surveillance cultivate a sense of intimacy, borne of being seen between consumer and brand. In other words, I advocate for recognizing the subjectification of contemporary practices of platform surveillance, in addition to its structural elements.
\end{abstract}

\section{Surveillance, Data, and the Business Logic of Amazon's Plafform}

This special issue invites us to consider what is distinctive about surveillance performed by platforms. There is a politics to the term platform, as Tarleton Gillespie (2010) has argued, in how it obscures the extractive, structuring, and enclosing nature of many platforms in favor of the image of a neutral and open foundation. There are multiple definitions of platforms in circulation (Gillespie 2010; Plantin, Lagoze, Edwards, and Sandvig 2018). One definition describes platforms as digital intermediaries - companies that provide some kind of digital space or software capability - that allow different stakeholders to interact (Gillespie 2010; Hagiu 2007). Amazon is a platform company in this sense, as it connects buyers and sellers through its online marketplace and fulfillment platforms as well as advertisers and consumers on its website.

A second way the term platform is understood in the digital economy is as hardware, software, or a service upon which other companies can build their own products and services (Montfort and Bogost 2009). For example, developers build games for people to play on Facebook, third parties integrate Google maps into their own websites and services, and companies build onto the Alexa digital assistant so consumers can access their services via voice (so-called "Alexa skills"). In this formulation, it is the programmability of the service, and therefore the ability of other entities to customize it for different uses that may not have been envisioned or anticipated by the platform provider, that makes it a platform (Andreessen 2007). 
A third insight about platforms in the digital economy, and the one primarily emphasized in this paper, is that their primary business, even with appearances to the contrary, is extracting and processing data (Srnicek 2017). In the digital economy, platform companies collect data about all the users on their platform and use that data to make their business activities more competitive. In addition, they sell these data to third parties, either directly or via products and services informed by that data. Amazon collects huge amounts of data about consumer behavior-including purchases, product wish lists, page clicks, time spent on pages, searches, emails opened, and products reviewed and rated - to create predictive algorithms that can be used to make its products and services ever more irresistible to consumers.

While Amazon began as simply an online retailer, initially of just books, since the earliest days it has recognized the value of its cybernetic commodities (Mosco 1996). As early as 1998, founder and CEO Jeff Bezos boasted of the power of collaborative filtering - algorithms that compare your purchases, searches, and other individual data with data from other, similar consumers - in order to predict what else you may purchase and thereby offer personalized recommendations (Brandt 2011). As former Amazon executive John Rossman (2016) puts it, Amazon's core business is creating optimal "consumer experience through personal recommendations, personalization, and data-based advertising models," which form the basis for marketing and advertising services to the many sellers that use the platform (97). In other words, "The Data is the Business Model" (96).

The importance of data to Amazon's core business model is clearly illustrated by the explosion of Prime, a sub-brand of Amazon that encompasses its subscription-based membership services, which could include (depending on the national market) free two-day shipping, streaming video, music streaming, e-book subscriptions, discounts at Amazon-owned Whole Foods Market, and more. Prime builds on the established practice among retailers, dating back to the 1990s, of trackable loyalty programs (Turow 2017). As Ned Rossiter (2016) argues, logistical media such as loyalty cards, digital coupons, and digital payments that track consumer movements and transactions turn shopping into the "economies of capture" that are foundational to surveillance capitalism (xiv). But what is distinctive about Prime is how it incentivizes doing as many activities and purchases as possible under the Amazon umbrella, which not only drives increased sales but also creates a fuller data picture of individual consumers. These data, in turn, drive the design of yet further products and services that create even greater incentives for Prime customers to stick with Amazon and not even consider shopping or consuming entertainment elsewhere. When you consider that there are an estimated 90 million Prime subscribers in the United States today and that these members are concentrated among Americans with higher incomes, the value of these data becomes clear (Columbus 2018).

Given the importance of consumer data to its operations, Amazon increasingly not only collects the data consumers happen to generate while using its services but also designs services whose purpose is, at least in part, to collect more data about consumers. The zenith of Amazon's surveillance capabilities is no doubt its family of Echo devices enabled by the artificial intelligence interactive-voice service Alexa, which connects to the cloud run by Amazon itself through Amazon Web Services. Alexa is similar to competing digital voice assistants like Apple's Siri and Google's Assistant, but with more cultural visibility, worldwide market penetration, and greater integration with a host of Internet-of-Things (IoT) devices many manufacturers produce. Amazon seeks to make Alexa an indispensable service to consumers, one that sweetens the granular forms of surveillance in more private spaces and situations that it now has the capability to gather, relative to the company's more established forms of digital surveillance.

\section{Alexa: Surveillance as a Service}

Amazon's current focus on IoT substantially extends the company's well-established business logic of collecting ever more detailed data about consumers. Amazon Web Services promotes the Connected Home as a rapidly growing opportunity for designing previously unconnected home devices - such as appliances, lights, plugs, thermostats, doorbells, door locks, and home entertainment devices-for the cloud. Through this rapidly growing array of "smart home" products, I argue that Amazon is selling surveillance as a service 
in two related ways. First, Amazon is on the leading edge of selling products and services consumers can use to conduct surveillance on their own domestic spaces. In terms of the Ring doorbell that has a built-in camera, for example, consumers can use their device from anywhere in the house, or even far from home, to see who or what (in terms of a delivered package) is on their doorstep without having to open the door. In addition, according to consumer product reviews, many of the security-focused devices work best with a monthly subscription to a service that also records all video that is taken by the device. In that sense, Amazon is not just selling products that provide surveillance but also selling it "as-a-service"-a broader trend in the digital economy where "no one wants to sell you anything anymore, they just want to rent it to you" (Barker 2017: para. 1).

Secondly, and perhaps more importantly, rather than surreptitious data collection (which of course it also does), Amazon increasingly offers surveillance as a key ingredient for providing personalized goods and services. As a brand, it embraces a logic whereby collecting personal details in domestic spaces is key to its personalized relationship with consumers. As Amazon explains to developers who seek to create skills for Alexa, "Alexa should remember context and past interactions, as well as knowing a customer's location and meaningful details in order to maintain familiarity and be more efficient in future exchanges" (bold in original, Amazon Alexa n.d.d: under "Tips for designing great voice experiences"). In other words, Amazon's desire and capability to watch and listen to its customers is increasingly presented as a feature, rather than a bug, even to consumers themselves.

Alexa is central to the aim of providing effortless, seamless, personalized service, as well as providing a personality to Amazon's service brand. Amazon launched its Echo smart speaker in 2014. The Echo suite of products - including the diminutive Echo Dot, the cylindrical Echo Smart Speaker, the alarm clock-like Echo Spot, and the larger, rectangular display of the Echo Show (among other products) - work with the Alexa AI "brain." In turn, other brands that build "skills" on the Alexa platform can integrate voicecontrolled services into their own products. Consumers can now also design their own customized skills through some applications, such as teaching Alexa to participate in family in-jokes or lead favorite games (Crum 2018).

Alexa and the Echo devices that support the service are creating a significant and wide-ranging infrastructure of surveillance. The Echo smart speakers are "always on" listening devices that are only supposed to send data to the cloud when activated by a watch word, although a few incidents of malfunction have already been widely reported in the press, raising fears that the devices might actually always be listening and recording people when they do not realize it (Day 2018a, 2018b). The newer devices, like the Echo Show, have cameras that are motion-sensitive, so "walking by is the visual equivalent of a wake-word" (Stevens 2017: para. 9).

The surveillance technologies Amazon is investing in position the company to be the ultimate service brand. As Bloomberg reporter Brad Stone (2018) has pointed out, Amazon's second biggest acquisition of another company to date is the aforementioned Ring in 2018, which makes Alexa-enabled doorbells and security cameras. This acquisition allows Amazon to not only provide its consumers with extensive surveillance capabilities via these devices but also to provide an integrated set of tools through which they can feel more secure about contracting with Amazon-provided home services, such as indoor package delivery, grocery delivery, and Amazon Home Services (which provides Amazon-approved services such as, so far, TV wall mounting, exercise equipment assembly, house cleaning, and installation of household items). Stone (2018) writes, "Alexa is a nice novelty now, great for serving up the weather, reading the news and hosting the occasional trivia game. But it will be really useful when it's the hub that lets people use their voice to arm their security systems, open locked doors and flash video of the person who's ringing the doorbell out front" (para. 2). Stone argues that, "To keep growing at 30 percent a year, Amazon has to start selling us services, not just stuff' (para. 7). I would argue, though, that Amazon has always been fundamentally a service brand.

Originally conceptualized by business scholar Leonard Berry (2000), service brands - as implied by the name - are organized around providing a consistent experience to their customers, especially important for 
companies that provide services but no tangible product. This can even be the case for brands that also sell actual products, such as Starbucks, which Berry argues is a service brand more so than a product brand. Similarly with Amazon, the real product is not so much the object you get but the quality of the serviceparticularly in speed, convenience, and price - that you receive in each and every interaction. Amazon's emphasis on personalization, recommendation, and the automation of consumption are all key components of its focus on being the ultimate service brand in the digital economy.

In the past, service brands achieved renown through the "personal touch" of a business owner or staff members or, beyond that, through services designed to be consistent and predictable for mass audiences. In the digital economy, however, service can be customized and personalized on a massive scale, thanks to the ability to collect data in every consumer interaction that can in turn be used to design future interactions. Digital legal scholar Tim Wu (2018) bemoans the "tyranny of convenience," which has persuaded so many of us to exchange our data privacy rights for seamless digital ecosystems where each individual service "remembers us." Platform companies like Amazon are ideally positioned to provide this kind of personalized convenience, where preferences, habits, and information across activity domains can be integrated into a seamless, "360 degree" service experience.

The rollout of the Echo Look, a smart speaker for the bedroom that comes with a camera designed to take full-length photos of the user, inspired communication scholar Zeynep Tufekci to raise the alarm bells about the increasing intrusiveness of smart home devices. With the help of the Style Guide skill, the Echo Look is designed for consumers to take pictures of themselves in two different outfits in order to receive a personalized suggestion for which one to wear. The advice is generated "using advanced machine learning algorithms and advice from fashion specialists" (Tufekci 2017), although the exact process or balance between the two is not clear (Goode 2017). Tufekci's (2017) fear is that we might be "[s]leepwalking into surveillance capitalism, which is evolving into data and computation authoritarianism, one cool service at a time." Whether health status, weight, subtle physical or behavioral signs of depression, or knowledge about the home from the background of the image, Tufekci points out that Amazon could conceivably use these data to sell us things beyond the stated purpose of the app, sell insights from the data to third parties who then market to us in a more customized way, or even sell the data to third parties who could use it to discriminate or target us politically. While most of these activities are ruled out by Amazon's policies, Tufekci advises skepticism about digital platforms' privacy promises. Whether via a hack, surreptitious cooperation with authorities, or eventually, public cooperation, the widespread adoption of Amazon's "smart" devices is creating an infrastructure of domestic surveillance that will no doubt be tempting for government, as well as for corporate America and Amazon itself, to use in ways beyond what consumers agree to or even imagine. Especially in countries like the United States, where privacy laws are not particularly strong, let alone in more authoritarian contexts, this should be cause for concern.

Similar to Tufekci, business scholar Shoshana Zuboff (2015), who coined the term "surveillance capitalism," is not so sure that the average consumer fully appreciates what tech companies can learn from our data traces, how disparate forms of data can be combined for the purpose of social and economic discrimination, or the extent to which aggregated personal data has economic value for platform companies. In the case of the kinds of data being collected by Alexa-enabled devices, there is an extra layer of economic benefit that is not necessarily associated with searches or page clicks. People's ongoing interactions with Alexa enhance its natural language-processing skills due to the logic of machine learning, whereby computer algorithms progressively improve their performance on particular tasks in response to new inputs and outcomes. This may help explain why Amazon's smart devices are almost permanently on sale- they are practically giving them away, according to some industry observers (e.g., Tiffany 2018). During the Cyber Monday of 2018, the Echo Dot was on sale for $\$ 19.99$ or $50 \%$ off, or it came for free with the purchase of an Amazon Fire stick. The Echo Look had a list price of \$199 but was on sale for \$50. Amazon's desire to consolidate its market leadership in smart speakers and AI voice assistants against competitors Apple and Google, thereby benefitting from winner-take-all network effects, also explains this pricing strategy. As Judith Shulevitz (2018) puts it in The Atlantic, "The company that succeeds in cornering the smart-speaker 
market will lock appliance manufacturers, app designers, and consumers into its ecosystem of devices and services" (para.6).

\section{Surveillance, Intimacy, and the Consumer-Brand Relation}

But what about the affective aspects of Alexa, and Amazon more broadly, as a brand that consistently and cheerfully offers us surveillance as a service? The affective turn in social theory encourages us to notice how intensity and feeling are produced in the body through interaction with others and the physical world (Clough and Halley 2007; Wetherell 2012). Scholars understand affect to be significant because of how it moves us to action (or discourages action) but also increasingly see it as a key element in subjectivity. While post-structural theory has long understood subjectivity, or our understanding of the self, to be shaped by how we are hailed by multiple discourses, affect theorists look beyond the discursive and the representational to how sensation and feeling, produced through encounters with other people, objects, and technologies, also shape the subject in profound ways (Lara et al. 2017). This theoretical insight is helpful for understanding Amazon, which has always been a brand with little explicit emotional content but a powerful affective relation with its consumers, building trust and relationality with consumers through interaction.

Fundamentally, Amazon offers to serve us by knowing us, including the domestic, private side of ourselves represented by our product searches, our purchases, the media we consume, and now with Alexa, what we say and how we say it. Alexa only deepens this relationship due to the affective nature of the human voice and the real-time experience of personalization in domestic space. In other words, Amazon's tools and techniques of surveillance create tremendous intimacy between consumer and brand-achieved through the sensations of being seen, heard, and known.

Perhaps the closest equivalent we have to understanding the rise of digital assistants and their impact on the subjectivities of those who use them is the history of domestic service. Commentators on Alexa have made this linkage, such as Judith Shulevitz, who describes the service as a "humble servant." Google chief economist Hal Varian takes inspiration from the classic insight that luxuries become necessities by "trickling down" from the upper classes to those below them in the social hierarchy, concluding that domestic help and, particularly, "personal assistants" are a luxury for the rich that middle and lower-income people aspire to (Zuboff 2015: 84). Now that tech companies like Google and Amazon provide a digital version of personal assistants, the tension between personalized service and the loss of privacy, long a dilemma faced only by the upper and upper-middle classes, is being newly negotiated by people of modest or middle-class means.

What we know about the history of domestic service comes primarily from novels and advice manuals to employers on how to manage their servants. Scholarship on these materials makes clear that the loss of privacy in exchange for the convenience of domestic help has a long history, especially as distinctions between public and private spheres became a greater issue of concern in Victorian England (Peak 2014). Another prominent theme was the forging of intimacy with hired help, or alternatively, a sense of betrayal when servants approached their positions purely for financial gain (Straub 2009). Seventeenth and eighteenth century literature about domestic servants is, of course, structured by the class differences inherent to that relationship, such that the intimacy, relationality, and possibilities for surveillance are all the more fraught when embedded in the need to demarcate and maintain social distance defined by class.

Alexa, and virtual assistants like her, offers domestic help for the middle classes but without the awkwardness of class difference or the need to make space in one's home for a living, breathing person. Interestingly, Amazon resists the term "assistant" for Alexa, instructing third parties developing Alexa skills to only refer to Alexa as "Amazon's cloud-based voice service" and never refer to it, or her, as a "personal assistant" or "virtual assistant" (Amazon Alexa n.d.b). This may well be in order to distinguish Alexa as much as possible from its main competitor, Google's Assistant. It also has the effect, perhaps unintended, of de-emphasizing Alexa's status as an assistant, which implies inequality. Unlike domestic servants, who 
are frequently dependent on their employer for their livelihoods and therefore vulnerable to abuse of different kinds, Alexa asserts her dignity and requirement for respect, to some extent, by deflecting abusive or demeaning questions (Amazon Alexa n.d.c). Amazon also explains that while Alexa is unfailingly polite, she need not say "please." Similarly, "Alexa is not overly apologetic, reserving 'sorry' for when she doesn't have the information or function requested" (Amazon Alexa n.d.a: under "When to Say "Sorry" "). As Shulevitz (2018) writes, "When we converse with our personal assistants, we bring them closer to our level" (para.9). Instructions to developers who are writing dialogue for Alexa skills emphasize that the relationship between Alexa and consumer should be familiar, friendly, and fairly egalitarian.

Amazon, personified as Alexa, creates an intimacy of familiarity; it's the brand that is part of everyday life. Amazon facilitates and encourages the experience of having one's self and one's needs seen by another, of being catered to, and the sensation of being placed at the center of someone else's universe. It makes this expectation of personalized service more broadly accessible than it has ever been, normalizing it as part of what it means to be a consumer in the digital age. At the same time, it normalizes surveillance by a corporate entity made warm and familiar through the persona of Alexa. While having our consumer needs and personal convenience placed on a pedestal might seem trivial, I suggest we should not underestimate this intimacy and the way it secures relationality, trust, and even dependence between consumer and brand.

\section{Conclusion}

The economic, political, and social implications of the explosion of surveillance by platforms is only beginning to become apparent. Certainly, the collection of ever greater amounts and kinds of data about consumers only contributes to the greater concentration of the tech industry, where network effects create tremendous barriers to entry and reduce meaningful market competition. A number of observers have raised the likelihood of a slippery slope between surveillance capitalism and political surveillance (Tufekci 2017; Zuboff 2015). Emerging reports from China, where shopping habits are one of the types of data that the government routinely requests from platform companies like Alibaba to identify people for prosecution, police investigation, or additional surveillance, suggest the kinds of outcomes that are within the realm of possibility (Lin and Chin 2017). Socially, the greater integration of AI services into our everyday lives, and the greater outsourcing of tasks onto digital assistants, have implications for domestic life and subjectivities we can only begin to glimpse. Among these are the forging of new kinds of affects between users and platforms and, along with that, the possibility that private space and the selves we inhabit in these spaces are being reconfigured by our entanglements with digital platform services.

\section{References}

Amazon Alexa. n.d.a. Function. Alexa Design Guide. https://developer.amazon.com/docs/alexa-design/design-function.html\#errors [accessed December 2, 2018].

Amazon Alexa. n.d.b. Marketing and Branding Guidelines. Alexa Design Guide. https://developer.amazon.com/docs/alexa-voiceservice/marketing-and-branding-guidelines.html\#messaging [accessed December 2, 2018]

Amazon Alexa. n.d.c. Trustbusters. Alexa Design Guide. https://developer.amazon.com/docs/alexa-design/trustbusters.html [accessed December 2, 2018].

Amazon Alexa. n.d.d. Voice Experiences. Alexa Design Guide. https://developer.amazon.com/docs/alexa-design/intro.html [accessed December 2018].

Andreessen, Marc. 2007. The Three Kinds of Platforms You Meet on the Internet. Pmarchive, September 16. https://pmarchive.com/three kinds of platforms you meet on the internet.html.

Barker, Deane. 2017. An Unofficial Guide to Whatever-as-a-Service. Gadgetopia, February 10. https:/gadgetopia.com/post/9981.

Berry, Leonard. L. 2000. Cultivating Service Brand Equity. Journal of the Academy of Marketing Science 28 (1): $128-137$. https://link.springer.com/content/pdf/10.1177/0092070300281012.pdf.

Brandt, Richard L. 2011. One Click: Jeff Bezos and the Rise of Amazon.com. New York: Portfolio/Penguin.

Columbus, Louis. 2018. 10 Charts that Will Change Your Perspective of Amazon Prime's Growth. Forbes, March 4. https:/www.forbes.com/sites/louiscolumbus/2018/03/04/10-charts-that-will-change-your-perspective-of-amazon-primesgrowth/\#477d19ed3fee.

Clough, Patricia Ticineto, and Jean Halley, eds. 2007. The Affective Turn: Theorizing the Social. Durham, NC: Duke University Press. 
Crum, Brian. 2018. Personalize Your Alexa Experience in Minutes with Alexa Skill Blueprints. Alexa Blog, April 19. https://developer.amazon.com/blogs/alexa/post/9c769704-b6c1-466d-ac90-2c386848e508/personalize-your-alexaexperience-in-minutes-with-alexa-skill-blueprints.

Day, Matt. 2018a. Amazon's Alexa Recorded and Shared a Conversation Without Consent, Report Says. The Seattle Times, May 24. https://www.seattletimes.com/business/amazon/amazons-alexa-recorded-and-shared-a-conversation-without-consentreport-says/.

Day, Matt. 2018b. Alexa is Laughing at People, Unprompted; Amazon is Working to Fix It. The Seattle Times, March 7. https://www.seattletimes.com/business/amazon/alexa-is-laughing-at-people-unprompted-amazon-is-working-to-fix-it/.

The Economist. 2017. Burying the Hachette: Manufacturing Struggles to Adapt. The Economist, October 26. https://www.economist.com/special-report/2017/10/26/manufacturing-struggles-to-adapt.

Gillespie, Tarleton. 2010. The Politics of 'Platforms.' New Media \& Society 12 (3): 347-364. https://doiorg.libproxy.lib.unc.edu/10.1177/1461444809342738

Goode, Lauren. 2017. Amazon's Echo Look Does More For Amazon Than It Does For Your Style. The Verge, July 6. https://www.theverge.com/2017/7/6/15924120/amazon-echo-look-review-camera-clothes-style.

Hagiu, Andrei. 2007. Merchant or Two-Sided Platform? Review of Network Economics 6 (2). http://www.rnejournal.com/articles/hagiu RNE june07.pdf.

Harvard Business Review. 2015. When Platforms Attack. Harvard Business Review, October: 30-31. https://hbr.org/2015/10/whenplatforms-attack.

Lara, Ali, Wen Liu, Colin Patrick Ashley, Akemi Nishida, Rachel Jane Liebert, and Michelle Billies. Affect and Subjectivity. Subjectivity 10 (1): 30-43. https://doi.org/10.1057/s41286-016-0020-8

Lin, Liza, and Josh Chin. 2017. China's Tech Giants Have a Second Job: Helping Beijing Spy on Its People. The Wall Street Journal, November 30. Proquest database.

Montfort, Nick, and Ian Bogost. 2009. Racing the Beam: The Atari Video Computer System. Cambridge, MA: The MIT Press.

Mosco, Vincent. 1996. The Political Economy of Communication. London: Sage Publications.

Peak, Anna. 2014. Servants and the Victorian Sensation Novel. SEL Studies in English Literature 1500-1900 54(4): 835-851. https://doi.org/10.1353/sel.2014.0042.

Plantin, Jean-Christophe, Carl Lagoze, Paul N. Edwards, and Christian Sandvig. 2018. Infrastructure Studies Meet Platform Studies in the Age of Google and Facebook. New Media \& Society 20 (1): 293-310.

Rossiter, Ned. 2016. Software, Infrastructure, Labor: A Media Theory of Logistical Nightmares. New York: Routledge.

Rossman, John. 2016. The Amazon Way on IoT: 10 Principles for Every Leader from the World's Leading Internet of Things Strategies. Clyde Hill Publishing.

Shulevitz, Judith. 2018. Alexa, Should We Trust You? The Atlantic, November. https:/www.theatlantic.com/magazine/archive/2018/11/alexa-how-will-you-change-us/570844/.

Srnicek, Nick. 2017. Platform Capitalism. Malden, MA: Polity Press.

Stevens, Laura. 2017. Amazon's New Echo Device Will Be Watching. Fox Business, May 11. https://www.foxbusiness.com/features/amazons-new-echo-device-will-be-watching.

Stone, Brad. 2018. Here's Why Amazon Bought a Doorbell Company. Bloomberg, March 5. https://www.bloomberg.com/news/articles/2018-03-05/here-s-why-amazon-bought-a-doorbell-company.

Straub, Kristina. 2009. Domestic Affairs: Intimacy, Eroticism, and Violence Between Servants and Masters in Eighteenth Century Britain. Baltimore, MD: Johns Hopkins University Press.

Tiffany, Kaitlyn. 2018. Smart Speakers Are Everywhere this Holiday Season, But They're Really a Gift for Big Tech Companies. Vox, November 27. https:/www.vox.com/the-goods/2018/11/26/18112631/cyber-monday-amazon-alexa-google-voiceassistant-war.

Tufekci, Zeynep. 2017. With this Data, Amazon Won't Be Able to Just Sell You Clothes or Judge You. It Could Analyze If You're Depressed or Pregnant and Much Else. April 26, 2017 Twitter Thread @zeynep. https://twitter.com/zeynep/status/857269154822443009?lang=en.

Turow, Joseph. 2017. The Aisles Have Eyes: How Retailers Track Your Shopping, Strip Your Privacy, and Define Your Power. New Haven, CT: Yale University Press.

Wetherell, Margaret. 2012. Affect and Emotion: A Social Science Understanding. London: The Open University Press.

$\mathrm{Wu}$, Tim. 2018. The Tyranny of Convenience. The New York Times, February 16. https:/www.nytimes.com/2018/02/16/opinion/sunday/tyranny-convenience.html.

Zuboff, Shoshana. 2015. Big Other: Surveillance Capitalism and the Prospects of an Information Civilization. Journal of Information Technology 30: 75-89. https://doi.org/10.1057/jit.2015.5. 